\title{
ORAL HEALTH RELATED QUALITY OF LIFE AND PERIODONTAL STATUS OF A SELECTED MALAYSIAN ADULT POPULATION: A PILOT STUDY
}

N.S. Abdullah, N.F.M. Radzali, R. Saub, R.D. Vaithilingam. Oral Health Related Quality of Life and Periodontal Status of A Selected Malaysian Adult Population: A Pilot Study. Annal Dent Univ Malaya 2013 (2): 16-23

\begin{abstract}
Aim: To assess the oral health related quality of life (OHQoL) of a selected population of Malaysian adults and to compare the OHQoL by periodontal status. Material \& Methods: This cross-sectional study comprises a convenient sampling of fifty subjects from the Primary Care Unit, Faculty of Dentistry, University of Malaya. OHQoL was assessed using the Malaysian version of Oral Health Impact Profile-14 (OHIP-14). Basic periodontal examination (BPE) was performed on all subjects to determine their periodontal status. Descriptive statistics and bivariate analysis were performed. Results: Psychological discomfort, physical pain and psychological disability domains were the most affected dimensions in this population. Subjects with income levels $>$ RM2,500 had higher impacts on their OHQoL as compared to those from other income levels $(\mathrm{p}<0.05) .78 \%$ of the subjects had some form of periodontitis (BPE scores 3 or 4) with the other $22 \%$ recording healthy/ gingivitis status (BPE 0,1 or 2). Subjects with periodontitis experienced higher impacts on OHQoL as compared to those with healthy/ gingivitis in nearly all domains $(\mathrm{p}>0.05)$. Conclusion: Subjects with high income levels had high impacts on their OHQoL. Those with periodontitis experienced higher impacts on their OHQoL as compared to those who had a healthy periodontium or gingivitis and affected a wide range of domains of quality of life.
\end{abstract}

Keywords: Oral health related quality of life, chronic periodontits, basic periodontal examination, oral health impact profile, gingivitis.

\section{INTRODUCTION}

Oral health related quality of life (OHQoL) has been defined as a multidimensional construct that reflects people's comfort when eating, sleeping and during interaction; their self-esteem; and their satisfaction with respect to their oral health (1). Several researchers $(2,3)$ identified the shift in the perception of health from merely the absence of disease and infirmity to complete physical, mental and social wellbeing as the key issue in the conception of health related quality of life (HRQoL) and,
Original Article

N.S. Abdullah', N.F.M. Radzali', R. Saub ${ }^{3}$, R.D.
Vaithilingam ${ }^{4}$
${ }^{1}$ Faculty of Dentistry, University of Malaya, Kuala
Lumpur, Malaysia
${ }^{2}$ Faculty of Dentistry, University of Malaya, Kuala
Lumpur, Malaysia
${ }^{3}$ Department of Community Dentistry, Faculty of
Dentistry, University of Malaya, Kuala Lumpur,
Malaysia
${ }^{4}$ Department of Restorative Dentistry, Faculty of
Dentistry, University of Malaya, Kuala Lumpur,
Malaysia
Corresponding Author:
Dr. Rathna Devi Vaithilingam
Email: rathna@um.edu.my

subsequently OHQoL. OHQoL is therefore an individual's assessment of how the following affect his/her well-being: functional factors, psychological factors, social factors, and experience of pain/discomfort in relation to orofacial concerns (3). Various tools have been used to measure OHQoL such as the OHQoL-UK, Geriatric (General) Oral Health Assessment Index (GOHAI) and Oral Health Impact Profile (OHIP).

Chronic periodontitis, the most common type of periodontal disease, is characterised by loss of clinical attachment due to the destruction of the adjacent periodontal supporting structures. National clinical oral epidemiological studies from developed countries have repeatedly estimated that over $90 \%$ of the general population has some form of periodontal disease $(4,5)$. In addition, studies have reported that between $10 \%$ and $20 \%$ of the population in most countries have severe forms of periodontal disease $(6,7)$. In a recent national oral health survey conducted in Malaysia, $94 \%$ of Malaysian adults were reported to present with periodontal conditions and $18.2 \%$ of these subjects have advanced periodontal disease (8).

A wide range of clinical signs and symptoms are produced in chronic periodontitis such as gum bleeding or recession and tooth mobility. Some of these signs and symptoms may have a considerable impact on the patients' day to day life or life quality (9). Traditionally, when assessing periodontal status, dental researchers have focused on clinically-driven outcome measures such as 
probing pocket depths and probing attachment levels. This has been done at the expense of more subjective patientdriven measures such as that perceived by functional status and psychological wellbeing (10-13) These clinicallydriven measures have been used particularly in the fields of cariology, oral rehabilitation, to some extent in oral surgery and oral medicine as well as periodontology. Over the last 15 years, there has been increasing interest in how periodontal disease and its treatment affect the well being of patients (14).

Measurements of the impact of periodontal conditions on OHQoL should be a part of the evaluation of oral health needs because clinical indicators alone cannot describe the satisfaction or symptoms dental patients' experience or their ability to perform daily activites. Studies have shown that patients with chronic periodontitis have reported negative impacts upon physical comfort, functional limitation, psychologic function or other domains of everyday life $(12,13,15)$. Thus far, no known study has reported the OHQoL impacts on periodontitis in Malaysians. The present study was carried out to assess the OHQoL of a selected population of Malaysian adults and to compare the OHQoL by periodontal status.

\section{MATERIALS AND METHOD}

\section{Study population}

This cross-sectional pilot study enrolled patients using a convenient sampling method from the Primary Care Unit, Faculty of Dentistry, University of Malaya. Subjects who fulfilled the inclusion/ exclusion criteria were selected. The inclusion criteria were individuals aged 30 years and older, had at least 12 teeth present (excluding third molars) and subjects were free from systemic diseases. Subjects who had received periodontal treatment or antibiotics within the past 4 months or who were pregnant were excluded from the study. The nature of the study was explained to the subjects. A written informed consent was obtained from all subjects who wished to participate in the study. The examination period was between June to August 2011 and a total of 50 subjects enrolled in this study. Ethical approval was obtained from the Ethics Committee, Faculty of Dentistry, University of Malaya (DF PE1103/0037(L)).

\section{Questionnaire}

The questionnaire gathered information on sociodemographics of subjects including age, gender, ethnicity, level of education and income level. Subjects were also enquired on oral health related habits like smoking habits, alcohol consumption and dental visits, as well as oral health practices such as brushing frequency, interdental cleaning and mouth rinsing.
The OHQoL was assessed using the Malaysian version of the Oral Health Impact Profile (OHIP)-14 which contains 14 items that was derived and validated by Saub et al (2005). The Malaysian OHIP-14 is specifically tailored to the Malaysian population and is available in English or Malay translation $(16,17)$. Subjects were asked to rate the impact of their oral health on 14 key areas of OHQoL which were grouped under 7 different domains, which are Functional Limitation, Physical Pain, Psychological Discomfort, Physical disability, Psychological disability, Social disability and Handicap. The questionnaire was conducted as a face-to-face interview.

\section{Basic periodontal examination}

Four examiners, comprising a periodontist and three dentists (who have been trained to use Basic periodontal examination [BPE]) attached to the Primary Care Unit carried out the oral examination. BPE was used to screen all subjects to determine the periodontal status of these subjects. The WHO probe which is a tapered, rodlike instrument and calibrated in millimetres with blunt rounded tip was used for the BPE. BPE divides the full dentition into six sextants. These six sextants consists of i) four groups of teeth each comprising molars (excluding third molars) and premolars of one side of one jaw and ii) two groups of teeth each comprising canines and incisors of one jaw. All teeth in the sextants were examined. The probe was inserted into the sulci/ pockets around the teeth in each sextant and the highest score for each sextant was recorded. BPE scores were given as $0=$ Healthy, $1=$ Bleeding on probing, $2=$ Presence of calculus or plaque retention factors, $3=$ Probing depth between $3.5 \mathrm{~mm}$ and $5.5 \mathrm{~mm}$ and $4=$ Probing depth more than $5.5 \mathrm{~mm}$. Before the study commenced, intra and inter-examiner reproducibility was conducted on 7 subjects and all examiners showed good reproducibility (All kappa scores were more than $80 \%$ ). The highest score recorded for each subject was determined as the subject score. Patients were then divided into two categories: healthy/gingivitis when their BPE score was 0,1 or 2 and periodontitis if their BPE scores were 3 or 4 .

\section{Data Analysis}

For each item in the OHIP questionnaire, subjects were given a Likert scale chart to choose answers from a six point scale: $1=$ very often, $2=$ quite often, $3=$ sometimes, $4=$ seldom, 5=never and 6=don't know (18). Missing value and "don't know" responses were imputed by the mean for the question. Two parameters for OHIP were computed (19): prevalence of impact (the percentage of subjects reporting impacts "very often/ quite often", "sometimes" or "seldom/ never") and severity (the sum of response codes of the 14 items). For the prevalence of impact, subjects reporting categories "very often/ quite often" are considered to have high impact", "sometimes" 
as moderate impact and "seldom/ never" as having low impact. Given the response codes, OHIP scores can range from 14 to 70; lower values indicating more frequent impact (9).

Since the data was not normally distributed and sample size was small, non-parametric tests, MannWhitney U test and Kruskall Wallis was used to analyse the difference between total OHIP-14 score with sample characteristics, oral hygiene practices/ habits and oral health status. The level of significance was set at 0.05 for all tests. Statistical analysis was done using the SPSS 12.0 statistical package.

\section{RESULTS}

\section{Sociodemographic characteristics and mean OHIP scores of all subjects}

A total of 50 subjects with age ranging from 30-74 years comprising of 23 males (46\%) and 26 females (52\%) were examined in this study (Table 1). The majority of subjects (94\%) had completed their education up to secondary school level.

No significant differences were detected between age, ethnicity, gender and educational levels and OHIP scores. However, income level had a significant impact on OHQoL. Subjects earning RM1,500- RM2,500 (middle

Table 1: Sociodemographic characteristics and mean OHIP scores of sample population

\begin{tabular}{|c|c|c|c|c|c|}
\hline & \multicolumn{5}{|c|}{ OHIP scores } \\
\hline Characteristics & $\mathrm{n}(\%)$ & mean & $95 \% \mathrm{Cl}$ & median & p-value* \\
\hline $\begin{array}{l}\text { Age } \\
30-44 \text { years } \\
45-59 \text { years } \\
60-74 \text { years }\end{array}$ & $\begin{array}{l}27(54) \\
16(32) \\
7(14)\end{array}$ & $\begin{array}{l}59.2 \\
57.1 \\
60.6\end{array}$ & $\begin{array}{l}56.9-61.6 \\
53.0-61.2 \\
53.1-68.0\end{array}$ & $\begin{array}{l}61.0 \\
59.0 \\
64.0\end{array}$ & 0.47 \\
\hline $\begin{array}{l}\text { Ethnicity } \\
\text { Malay } \\
\text { Chinese } \\
\text { Indian }\end{array}$ & $\begin{array}{c}22(44) \\
24(48) \\
4(8)\end{array}$ & $\begin{array}{l}58.5 \\
58.9 \\
59.3\end{array}$ & $\begin{array}{c}54.98-61.9 \\
56.2-61.6 \\
51.7-66.8\end{array}$ & $\begin{array}{l}61.0 \\
59.5 \\
57.5\end{array}$ & 0.91 \\
\hline $\begin{array}{l}\text { Gender } \\
\text { Male } \\
\text { Female }\end{array}$ & $\begin{array}{l}23(46) \\
26(52)\end{array}$ & $\begin{array}{l}57.8 \\
59.4\end{array}$ & $\begin{array}{l}54.2-61.5 \\
57.3-61.5\end{array}$ & $\begin{array}{l}60.0 \\
60.5\end{array}$ & 0.82 \\
\hline $\begin{array}{l}\text { Education level } \\
\text { Primary } \\
\text { Secondary } \\
\text { Tertiary }\end{array}$ & $\begin{array}{c}3(6) \\
27(54) \\
20(40)\end{array}$ & $\begin{array}{l}61.3 \\
58.6 \\
58.6\end{array}$ & $\begin{array}{l}55.1-67.6 \\
55.4-61.7 \\
55.8-61.3\end{array}$ & $\begin{array}{c}61 \\
60 \\
60.5\end{array}$ & 0.82 \\
\hline $\begin{array}{l}\text { Income level } \\
<R M 1,500 \\
R M 1,500-R M \\
2,500 \\
>R M 2,500\end{array}$ & $\begin{array}{l}15(30) \\
20(40)\end{array}$ & $\begin{array}{l}58.9 \\
61.6\end{array}$ & $\begin{array}{l}56.1-61.8 \\
59.9-63.3\end{array}$ & $\begin{array}{l}59 \\
61\end{array}$ & 0.04 \\
\hline
\end{tabular}

* Refers to Mann-Whitney test for gender and Kruskal-Wallis test for age ethnicity, education level, and income level. income group) had the lowest impact on their OHQoL while those earning $>$ RM2,500 had the highest impact on their OHQoL ( $\mathrm{p}=0.04)$.

\section{Habits / oral health practices and mean OHIP scores of all subjects}

Oral health practices/habits of subjects were assessed as shown in Table 2. Seventy percent of the subjects never smoked and $72 \%$ of them never consumed alcohol. Majority of the subjects brush their teeth twice daily

Table 2: Habits/ Oral health practices and mean OHIP scores of all subjects

\begin{tabular}{|c|c|c|c|c|c|}
\hline \multirow[b]{2}{*}{$\begin{array}{l}\text { Habits/ } \\
\text { Practices }\end{array}$} & \multicolumn{5}{|c|}{ OHIP scores } \\
\hline & n (\%) & mean & $95 \% \mathrm{Cl}$ & median & p-value* \\
\hline \multicolumn{6}{|c|}{ Smoking status } \\
\hline Current & $12(24)$ & 56.1 & $49.7-62.4$ & 59 & \multirow{3}{*}{0.87} \\
\hline Former & $3(6)$ & 59.3 & $47.9-70.8$ & 62 & \\
\hline Never & $35(70)$ & 59.6 & $57.7-61.5$ & 61 & \\
\hline \multicolumn{6}{|l|}{ Alcohol } \\
\hline & $10(20)$ & 55.7 & $50.7-60.7$ & 55.5 & \multirow{3}{*}{0.24} \\
\hline Former & $4(8)$ & 60.5 & $53.4-67.6$ & 60 & \\
\hline Never & $36(72)$ & 59.4 & $57.0-61.7$ & 61 & \\
\hline \multicolumn{6}{|l|}{ Brushing } \\
\hline $1 x /$ day & $3(6)$ & 53.3 & $38.4-68.3$ & 54 & \multirow{3}{*}{0.09} \\
\hline $2 x / d a y$ & $41(82)$ & 59.3 & $57.2-61.4$ & 61 & \\
\hline$>2 x /$ day & $6(12)$ & 57.5 & $49.6-65.4$ & 60 & \\
\hline \multicolumn{6}{|c|}{ Dental visit } \\
\hline$<2 x / y e a r$ & $4(8)$ & 56.8 & $43.40-70.5$ & 57 & \multirow{3}{*}{0.79} \\
\hline$>2 x /$ year & $12(24)$ & 59.4 & 55.3-63.5 & 59.5 & \\
\hline Irregular & 34 (68) & 58.7 & $56.3-61.1$ & 61 & \\
\hline \multicolumn{6}{|l|}{$\begin{array}{l}\text { Interdental } \\
\text { cleaning }\end{array}$} \\
\hline Yes & $33(66)$ & 57.5 & $54.8-60.1$ & 59 & \multirow[t]{2}{*}{0.13} \\
\hline No & $17(34)$ & 61.1 & 59-63.2 & 61 & \\
\hline \multicolumn{6}{|l|}{ Rinsing } \\
\hline Yes & $32(64)$ & 58.1 & $55.6-60.6$ & 69.5 & \multirow[t]{2}{*}{0.30} \\
\hline No & $18(36)$ & 59.8 & $56.5-63.1$ & 61 & \\
\hline
\end{tabular}

* Refers to Mann-Whitney test for interdental cleaning and rinsing and Kruskal-Wallis test for smoking status, alcohol consumption, brushing frequency and dental visits.

$(82 \%)$ and were irregular dental attendees $(68 \%)$. Sixty six percent of the subjects performed interdental cleaning while $64 \%$ use mouth rinse. There were no significant differences between practices/ habits like smoking, consuming alcohol, dental visits, interdental cleaning, and mouth-rinsing with mean OHIP scores. 


\section{Oral health status and mean OHIP scores of all subjects}

Oral health status of the sample population was assessed as shown in Table 3. Majority of the subjects had less than 5 missing teeth (80\%). $78 \%$ of the subjects had some form of periodontitis (BPE scores 3 or 4 ) but only $22 \%$ of them had a periodontium that was either healthy or with gingivitis (BPE scores 0,1 or 2).

Table 3: Oral Health status and mean OHIP scores of all subjects

\begin{tabular}{|c|c|c|c|c|c|}
\hline \multirow[b]{2}{*}{$\begin{array}{l}\text { Oral health } \\
\text { status }\end{array}$} & \multicolumn{5}{|c|}{ OHIP scores } \\
\hline & n (\%) & mean & $95 \% \mathrm{Cl}$ & median & p-value* \\
\hline \multirow{3}{*}{$\begin{array}{l}\text { No of missing } \\
\text { teeth } \\
<5 \text { teeth } \\
\geq 5 \text { teeth }\end{array}$} & & & & & \\
\hline & $40(80)$ & 58.7 & $56.5-60.9$ & 60.5 & 0.90 \\
\hline & $10(20)$ & 58.7 & 53.9-63.5 & 60 & \\
\hline \multicolumn{6}{|l|}{$\begin{array}{l}\text { Periodontal } \\
\text { status } \\
\text { - Healthy }\end{array}$} \\
\hline $\begin{array}{l}\text { Gingivitis } \\
\text { (BPE 0\&1\&2) }\end{array}$ & $11(22)$ & 60.6 & $57.0-64.3$ & 61 & 0.50 \\
\hline $\begin{array}{l}\text { - Periodontitis, } \\
\text { (BPE 3\&4\&*) }\end{array}$ & $39(78)$ & 58.2 & $55.9-60.5$ & 60 & \\
\hline
\end{tabular}

* Refers to Mann-Whitney test for number of missing teeth/ periodontal status

Mean OHIP scores and oral health status of all subjects were assessed as shown in Table 3. There was no significant difference between number of missing teeth and with mean OHIP scores. The mean OHIP scores for healthy/ gingivitis was $60.64( \pm 5.4)$ while the mean OHIP scores for periodontitis subjects was $58.18( \pm 7.1)$. This demonstrates that the periodontitis subjects have a higher impact on their OHQoL. However this difference was not significant.

\section{Prevalence of impact for individual items response for all subjects.}

The prevalence of OHQoL impact of all 50 subjects was assessed as shown in Table 4. The most affected domains of quality of life were psychological discomfort, physical pain and psychological disability domains.

Under the psychological discomfort domain, majority of subjects reported that food impaction (28\%) and feeling shy because of problems with their oral condition $(8 \%)$ would affect their OHQoL. For the physical pain domain, $12 \%$ of the subjects reported that they often felt discomfort while eating while another $6 \%$ often experienced oral ulcers. Under the functional limitation domain, only $6 \%$ of subjects reported that difficulty in chewing food and having bad breath affects them at a frequent rate. For the handicap domain, $6 \%$ of subjects reported spending money $\&$ feeling less confident of their oral condition. Under the physical disability domain, $6 \%$ of subjects reported that they avoided eating certain food.

Table 4: Prevalence of impact for individual items response for total population

\begin{tabular}{lccc}
\hline Items & $\begin{array}{c}\text { Very often/ } \\
\text { quite often } \\
\mathrm{n}(\%)\end{array}$ & $\begin{array}{c}\text { Sometimes } \\
\mathrm{n}(\%)\end{array}$ & $\begin{array}{c}\text { Seldom/ } \\
\text { never } \mathrm{n} \\
(\%)\end{array}$ \\
\hline $\begin{array}{l}\text { Functional limitations } \\
\text { Difficulty in chewing }\end{array}$ & $3(6)$ & $23(46)$ & $24(48)$ \\
Bad breath & $3(6)$ & $29(58)$ & $18(36)$ \\
\hline $\begin{array}{l}\text { Physical pain } \\
\text { Eating discomfort }\end{array}$ & $6(12)$ & $21(42)$ & $23(46)$ \\
Oral ulcer & $3(6)$ & $33(66)$ & $14(28)$ \\
\hline $\begin{array}{l}\text { Psychological } \\
\text { discomfort }\end{array}$ & & & \\
$\begin{array}{l}\text { Food lodged } \\
\text { Shy }\end{array}$ & $14(28)$ & $28(56)$ & $8(16)$ \\
\hline $\begin{array}{l}\text { Physical disability } \\
\text { Avoid eating }\end{array}$ & $4(8)$ & $16(32)$ & $30(60)$ \\
$\begin{array}{l}\text { Avoid smiling } \\
\text { Psychological }\end{array}$ & $3(6)$ & $16(32)$ & $31(62)$ \\
disability & $1(2)$ & $13(26)$ & $36(72)$ \\
$\begin{array}{l}\text { Sleep disturbance } \\
\text { Concentration } \\
\text { disturbance }\end{array}$ & $4(8)$ & $22(44)$ & $24(48)$ \\
\hline $\begin{array}{l}\text { Social disability } \\
\text { Avoid going out } \\
\text { Daily activities disturbed }\end{array}$ & $2(4)$ & $24(48)$ & $24(48)$ \\
\hline $\begin{array}{l}\text { Handicap } \\
\text { Spending money }\end{array}$ & $1(2)$ & $7(14)$ & $42(84)$ \\
Less confident & $3(6)$ & $24(48)$ & $23(46)$ \\
\hline & $3(6)$ & $15(30)$ & $32(64)$ \\
\hline
\end{tabular}

\section{The prevalence of impact for individual items response by periodontal status}

The prevalence of impact for individual items response by periodontal status (healthy/ gingivitis and periodontitis subjects) are as shown in Table 5. The percentage for individual items response for periodontitis subjects were higher than that reported for the healthy/ gingivitis group in all domains except for 'feeling shy' (psychological discomfort domain), 'to avoid eating' (physical disability domain) and 'sleep disturbance' (psychological disability domain). Food getting lodged between teeth (psychological discomfort domain) had the highest impact in the periodontitis group as compared to the healthy/ gingivitis group. 
Table 5: The prevalence of impact for individual items response by periodontal status

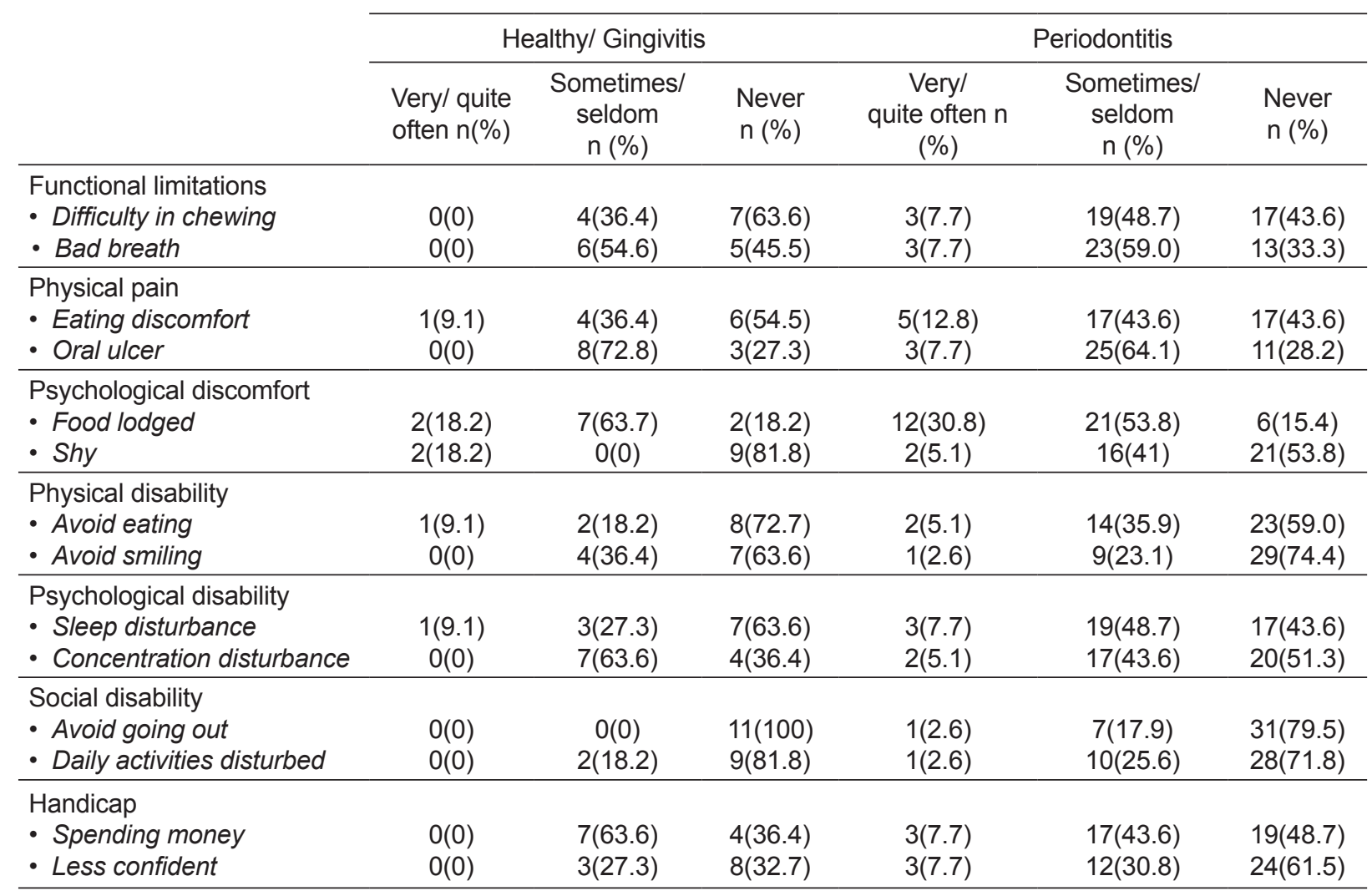

\section{DISCUSSION}

The present study investigates the OHQoL as well as periodontal status and its impact on the quality of life of adult subjects who attended the Primary Care Unit, Faculty of Dentistry, University of Malaya. The findings in this study demonstrated high impacts on their OHQoL in the psychological discomfort, physical pain and psychological disability domains. This is in agreement with McGrath \& Bedi (2002) who concluded that effect of oral health on quality of life for the British population was considerable, with many individuals experiencing negative impacts across a broad range of physical, social and psychological aspects of life quality (20). An understanding and knowledge of the relationship between clinical and subjective indicators will enable the dental practitioner to make rational decisions about what oral conditions require treatment and the type of treatment that is needed for a given condition with the available resources (21).

Income level was the only sociodemographic factor found to be significant with the OHQoL. Those who have income levels $>$ RM2,500 had higher impacts on their OHQoL than those subjects with other income levels. This finding is in agreement with Araújo et al. (2010) (15) who detected that OHQoL impacts were significantly associated with income level. The reason for the higher income group having higher impacts on their $\mathrm{OHQ}$ may be due to their higher expectations of oral health as compared to the lower income categories (20).

No significant difference was found between gender and OHQoL in this study. This finding is in agreement with Fernandes et al. (2006) (22). In contrast, Mason et al (2006) found a positive relationship between gender and OHQoL (23). They concluded that life course influences on oral-health- related quality of life appear different for men and women, which may have implications for the effectiveness of public health interventions and health promotion. In the current study we have failed to show this difference and this may be due to the small sample size in this pilot study. A future study with an adequately powered sample size may be able to capture this difference.

In this study there was no significant difference between age and OHQoL. These findings are not in agreement with findings from previous studies $(15,20$, 24). McGrath and Bedi (2002) demonstrated that OHQoL tended to decrease with age (20). In contrast, Araújo et al. (2010) and Steele et al (2004) showed an increase in OHQoL with increasing age $(14,24)$. Araújo et al. (2010) concluded that these differences may indicate distinct differences in the way oral health is perceived upon quality of life at different ages or stages in life (15). Bryla et al. (2013) demonstrated that age on its own was 
not a determining factor but when combined with other variables such as diseases as well as mental and physical disabilities it could significantly decrease quality of life. In the current study, all subjects were systemically healthy with no mental or physical disabilities and this may explain the lack of an association between age and OHQoL (25).

Fernandes et al. (2006) found the impacts on OHQoL of patients who were smokers to be higher than non-smokers (22). In the present study, current smokers showed a higher trend for having impacts on their OHQoL compared to former smokers and never smokers; however this difference was not significant. The negative effect of smoking on OHQoL is probably due to the harmful effects of smoking on oral tissues (26).

In this study, $22 \%$ of the sample population was diagnosed as being periodontally healthy/ gingivitis while $78 \%$ of the sample population was diagnosed as having periodontitis. Periodontitis subjects demonstrated higher impacts on their OHQoL as compared to healthy/ gingivitis subjects but the difference was however not significant. The findings in the present study corroborate with the study by Araújo et al. (2010) who demonstrated that highest impact on OHQoL were those of patients with a diagnosis of chronic or aggressive periodontitis (15). Needleman et al (2004) detected that OHQoL-UK scores were correlated with the number of teeth with pocket depths of $5 \mathrm{~mm}$ or more (12). In the present study, the reason for there not being a significant difference could have been the small sample size ( 50 subjects) as compared to the study by Needleman et al (2004) and Araujo et al. where the numbers were 205 and 401 subjects respectively $(12,15)$.

The finding that with decreasing number of teeth, the perceived OHQoL tended to decrease has been observed in previous studies $(24,27,28)$. In the present study, there was no significant difference between numbers of missing teeth with OHQoL and again this may have been due to the small sample size in the current study.

In this study, individual items response for OHIP-14 in periodontitis subjects were higher than that reported for the healthy/ gingivitis group in nearly all domains. Food getting lodged between teeth (psychological discomfort domain) had the highest impact in the periodontitis group as compared to the healthy/ gingivitis group. This is in agreement with Saito et al. (2010) who detected that pain, eating and chewing, and psychologic function were identified as compromised OHQoL domains (29). The negative impacts faced across this broad range of domains demonstrate that the effect of periodontitis on quality of life of this selected Malaysian population was considerable. This finding may change the perception of chronic periodontitis being categorised as a silent disease.

The current study was designed to eliminate all probable confounding factors such as systemic diseases and pregnancy. Self-perceived health is thought to be the end result of the effects of systemic diseases, disabilities, and limitations of daily activities (30). Wee et al. (2005) demonstrated that subjects with diabetes and multiple co-existing chronic medical conditions have reported poorer HRQoL than those without these conditions (31). They found that the co-existence of other chronic medical conditions in diabetic subjects led to further lowering of HRQoL in an additive, rather than synergistic or subtractive fashion. In this study, we excluded patients who had systemic diseases such as Type 1 or Type 2 diabetes as well as pregnant subjects in order to eliminate the effect it may have on their quality of life.

This study has used basic periodontal examination (BPE) to assess the periodontal status. BPE assessments have the marked advantage of being quick with minimal subject discomfort. However, BPE has the potential to underestimate the prevalence of periodontal breakdown in populations with less susceptibility or overestimate the prevalence when based on the measurements of lifetime cumulative attachment loss $(32,33,34)$. In contrast, full mouth charting assessments as performed in a number of epidemiological studies will provide optimal examination of periodontal conditions (35). Although it is desirable to record as many sites as possible to increase the probability of detecting disease prevalence, one of the main drawbacks of full mouth assessments is that it can be time consuming. BPE is currently being used as a screening tool for all periodontal patients in the Primary Care Unit of the Faculty of Dentistry, University of Malaya. In this study, since the patients were obtained from this unit, it was decided that BPE would be used as the examination method to determine the periodontal status of the subjects in this study.

Various methods have been used to develop oral specific health status measures. Since its development, the OHIP-14 has been preferred to the OHIP-49 by a number of researchers due to its practicality (22). In this study the OHIP-14 questionnaire was done as a two way interview whereby the evaluator asks the questions and the subjects are given a flash card with the range of answers from which they can choose. This two-way interaction method between subject's and evaluators reduces error, dishonesty and inaccuracy when compared to one way interaction method while answering the OHIP-14 questionnaire.

\section{CONCLUSION}

In this study, the selected population had high impacts on their OHQoL in the psychological discomfort, physical pain and psychological disability domains. Those with income levels > RM2,500 had higher impacts on their OHQoL than those subjects from other income levels. Subjects with periodontitis demonstrated higher impacts on their OHQoL as compared to those who have healthy periodontium/ gingivitis, affecting a wide range of OHQoL domains. The findings from this pilot study will 
form the basis for implementing a future study with a larger sample size which will increase the validity of this study. It is also recommended that future studies should include assessments of full mouth periodontal charting as compared to BPE as this will increase the probability of detecting disease prevalence.

\section{ACKNOWLEDGEMENTS}

The authors would like to thank Dr Leilawati Sulaiman, Dr Anand Ramanathan and Dr Fadya Abdulfattah Mustafa as well as the staff of the Primary Care Unit, Faculty of Dentistry, University of Malaya for their assistance is carrying out this research. This study was supported by a research grant received from the Ministry of Higher Education (UM.C/HIR/MOHE/DENT/ 04).

\section{REFERENCES}

1. DHHS. Oral health in America: a report of the Surgeon General. US Department of Health and Human Services and National Institute of Dental and Craniofacial Research. 2000 Rockville, MD: National Institutes of Health

2. Atchison KA, Gift HC. Perceived Oral Health in a Diverse Sample. Adv Dent Res 1997; 11(2):272-80

3. Inglehart MR, Bagramian RA, eds. Oral healthrelated quality of life. Illinois, Quintessence Publishing Co. Inc. 2000

4. Borrell LN, Burt BA, Gillespie BW, Lynch J, Neighbors H. Periodontitis in the United States: beyond black and white. J Public Health Dent. 2002; 62:92-101.

5. Morris AJ, Steele J, White DA. The oral cleanliness and periodontal health of UK adults in 1998. $\mathrm{Br}$ Dent J. 2002; 191(4):186-92.

6. Albandar J, Brunelle J, Kingman A. Destructive periodontal disease in adults 30 years of age and older in the United States 1988-1994. J Periodontol. 1999; 70:13-29.

7. Hugoson A, Laurell L. A prospective longitudinal study on periodontal bone height changes in a Swedish population. J Clin Periodontol 2000;27:665674.
8. Oral Health Division, Ministry of Health Malaysia. National Oral Health Survey of Adults 2010 (NOHSA 2010): Initial findings (Unweighted data). October 2012.

9. Locker, D. Measuring Oral Health: a conceptual framework. Community Dent Health 1998; 5: 3-18.

10. Hujoel PP, Leroux BG, DeRouen TA, Powell LV, Kiyak HA. Evaluating the validity of probing attachment loss as a surrogate for tooth mortality in a clinical trial on the elderly. J Dent Res 1997;76(4):858-66.

11. Fardal O, Johannessen AC, Linden GJ. Patient perceptions of periodontal therapy completed in a periodontal practice. J Periodontol 2002;73(9):1060-6.

12. Needleman, I., McGrath, C., Floyd, P. Biddle, A. Impact of oral health on the life quality of periodontal patients. J Clin Periodontol 2004; 31: 454-457.

13. Ng SK, Leung WK. Oral health-related quality of life and periodontal status. Community Dent Oral Epidemiol 2006; 34:114-122.

14. Matthews DC, McCulloch CA. Evaluating patient perceptions as short-term outcomes of periodontal treatment: a comparison of surgical and non-surgical therapy. J Periodontol 1993;64(10):990-7.

15. Araujo AC, Gusmão ES, Batista JE, Cimoes R. Impact of periodontal disease on quality of life. Quintessence Int 2010;41(6):e111-8.

16. Saub R, Locker D, Allison P. Derivation and validation of the short version of the Malaysian Oral Health Impact Profile. Community Dent Oral Epidemiol 2005; 33(5): 378-383.

17. Saub R, Locker D, Allison P, Disman M. Crosscultural adaptation of Oral Health Impact Profile (OHIP) for Malaysian adult population. Community Dent Health 2007; 24:166-175.

18. Slade GD. Derivation and validation of a short-form oral health impact profile. Community Dent Oral Epidemiol 1997; 25: 284-90 
19. Locker D, Quiñonez C. Functional and psychosocial impacts of oral disorders in Canadian adults: a national population survey. J Can Dent Assoc. 2009 Sep;75(7):521

20. McGrath C, Bedi R. Population based norming of the UK oral health related quality of life measure (OHQoL-UK). Br Dent J 2002;193(9):521-4

21. Ekanayake L, Perera I. The association between clinical oral health status and oral impacts experienced by older individuals in Sri Lanka. J Oral Rehabil 2004;31(9):831-6.

22. Fernandes MJ, Ruta DA, Ogden GR, Pitts NB, Ogston SA. Assessing oral health-related quality of life in general dental practice in Scotland: validation of the OHIP-14. Community Dent Oral Epidemiol 2006; 34: 53-62.

23. Mason, J, Pearce, MS, Walls AW, Parker L, Steele JG. How do factors at different stages of the life course contribute to oral-health related quality of life in middle age for men and women.; J Dent Res 2006; 85(3): 257-61

24. Steele JG, Sanders AE, Slade GD, Allen PF, Lahti S, Nuttall N, Spencer AJ. How do age and tooth loss affect oral health impacts and quality of life? A study comparing two national samples. Community Dent Oral Epidemiol 2004;32(2):107-14.

25. Bryla M, Burzy Ska M, Maniecka-Bry A I. Selfrated quality of life of city-dwelling elderly people benefitting from social help: results of a crosssectional study. Health Qual Life Outcomes. 2013;11(1):181.

26. Palmer RM, Wilson RF, Hasan AS, Scott DA. Mechanisms of action of environmental factorstobacco smoking. J Clin Periodontol 2005; 32(Suppl 6): 180-195.

27. Loureiro A, Costa F, da Costa J. The impact of periodontal disease on the quality of life of individuals with Down syndrome. Downs Syndr Res Pract 2007;12(1):50-4.
28. Aslund M, Pjetursson BE, Lang NP. Measuring oral health-related quality-of-life using OHQoLGE in periodontal patients presenting at the University of Berne, Switzerland. Oral Health Prev Dent. 2008;6(3):191-7.

29. Saito A, Hosaka Y, Kikuchi M, Akamatsu M, Fukaya C, Matsumoto S, et al. Effect of initial periodontal therapy on oral health-related quality of life in patients with periodontitis in Japan. J Periodontol 2010;81(7):1001-9.

30. Jones JA, Kressin NR, Miller DR, Orner MB, Garcia RI, Spiro A 3rd. Comparison of patientbased oral health outcome measures. Qual Life Res 2004;13:975-985.

31. Wee HL, Lee WW, Ravens-Sieberer U, Erhart M, Li SC. Validation of the English version of the KINDL generic children's health-relatedquality of life instrument for an Asian population--results from a pilot test. Qual Life Res 2005;14(4):1193-200

32. Beck JD, Loe H, Epidemiological principles in studying periodontal diseases. Periodontol 2000 1993;2:34-45.

33. Carlos JP, Wolfe MD, Kingman A. The extent and severity index: a simple method for use in epidemiologic studies of periodontal disease. J Clin Periodontol 1986;13(5):500-5.

34. Eaton KA, Duffy S, Griffiths GS, Gilthorpe MS, Johnson NW. The influence of partial and full-mouth recordings on estimates of prevalence and extent of lifetime cumulative attachment loss: a study in a population of young male military recruits. $\mathrm{J}$ Periodontol 2001;72(2):140-5.

35. Savage, A, Eaton KA, Moles DR, Needleman I. A systematic review of definitions of periodontitis and methods that have been used to identify this disease. J Clin Periodontol 2009; 36 (6): 458-467 